\title{
Estudo do crescimento de nanofitas de céria dopada com gadolínio por sistema de aquecimento por micro-ondas
}

\section{(Study of growth of gadolinium-doped ceria nanobelts by a hydrothermal microwave system)}

\author{
R. F. Gonçalves ${ }^{1}$, D. A. Castro' , M. R. C. Santos ${ }^{1}$, A. T. Figueiredo ${ }^{1}$, C. M. Barrado ${ }^{2}$, E. R. Leite, M. Godinho Jr. ${ }^{1}$ \\ ${ }^{I}$ Departamento de Química, Universidade Federal de Goiás, Av. Lamartine P. Avelar 1120, Catalão, GO 75704-020 \\ ${ }^{2}$ Instituto de Ciências Exatas e Naturais, Universidade Federal do Pará, R. Augusto Corrêa, Belém, PA, 0166075-110 \\ ${ }^{3}$ INCTMN, Departamento de Química, Universidade Federal de S. Carlos, Rod. Washington Luiz, km 235, S. Carlos,
} SP 13565-905

\begin{abstract}
Resumo
O óxido de cério (céria) tem atraído atenção devido às suas importantes aplicações, como em células a combustível de óxido sólido, catalisadores de gases de exaustão de automóveis, catalisadores para a obtenção de hidrogênio, bloqueadores de raios ultravioleta, biomateriais, entre outros. Controlar os métodos de síntese da céria é de grande importância para explicar ou prever essas propriedades. Desta forma, o objetivo deste trabalho foi estudar o crescimento de nanofitas de óxido de cério em um sistema hidrotérmico assistido por micro-ondas, no qual $8 \mathrm{~min}$ foram obtidas nanofitas com comprimentos próximos a $330 \mathrm{~nm}$, em 130 ${ }^{\circ} \mathrm{C}$ e pressão de $3 \mathrm{~atm}$. Os resultados colaboram para pesquisas em reformadores para obtenção de etanol e/ou anodos de células combustíveis de óxido sólido.

Palavras-chave: catalisadores, células a combustível, óxido de cério, aquecimento por micro-ondas, nanofitas.
\end{abstract}

Abstract

Cerium oxide (ceria) has attracted attention because of its important applications such as solid oxide fuel cells, catalysts for automobile exhaust gas, catalysts to obtain hydrogen, UV blockers, biomaterials, etc.. Control methods for synthesis of ceria are of great importance to explain or predict these properties. Thus, the objective of this work was to study the growth of cerium oxide nanobelts in a microwave-assisted hydrothermal system, where in $8 \mathrm{~min} 330 \mathrm{~nm}$ nanobelts were obtained at $130^{\circ} \mathrm{C}$ and $3 \mathrm{~atm}$. The results collaborate to the research on reformers for ethanol and/or solid oxide fuel cells anode.

Keywords: catalysts, fuel cells, cerium oxide, microwave heating, nanobelts.

\section{INTRODUÇÃO}

O dióxido de cério $\left(\mathrm{CeO}_{2}\right)$ ou céria é um material cerâmico que tem sido muito estudado por apresentar ampla utilização em células a combustível de óxido sólido, sensores eletroquímicos, materiais luminescentes, material para polimento, aditivo cerâmico, bloqueadores de UV, biomateriais [1-4]. Dentre os óxidos metálicos, a céria se destaca por possuir diversas propriedades físicas interessantes devido à sua configuração eletrônica, sendo hoje amplamente aplicada como catalisador para gases de exaustão, reforma de etanol na obtenção de hidrogênio, para síntese de compostos orgânicos e também como catalisadores em exaustores automotivos [58]. A céria tem a propriedade de absorver e liberar oxigênio sob condições reversíveis de oxidação e redução, processo este denominado estocagem de oxigênio. A causa deste efeito é uma transformação contínua e reversível entre o sesquióxido e o dióxido de cério $\left(\mathrm{Ce}_{2} \mathrm{O}_{3}\right.$ e $\mathrm{CeO}_{2}$, respectivamente), um pobre e outro rico em oxigênio, dependendo da concentração externa do gás [9]. A céria é também um condutor elétrico misto, isto é, condutor eletrônico e iônico e a condutividade eletrônica é dependente da temperatura e da pressão parcial de oxigênio [10]. Na céria, o íon metálico está cercado por oito ânions $\mathrm{O}^{2-}$ que formam os vértices do cubo. Este tipo de estrutura é relativamente aberta, o que o torna susceptível a inserção de uma variedade de dopantes. A inserção de dopantes com valência próxima $\left(\mathrm{M}^{\mathrm{x}-1}\right)$ a do íon a ser substituído e também com raio iônico próximo ( $\pm 15 \%$ do íon substituído) gera um maior número de vacâncias de oxigênio comparado ao mesmo material sem dopante [11]. Um dos íons metálicos que pode ser utilizado como dopante da céria e que é o foco deste estudo é o íon gadolínio. O gadolínio quando na forma de óxido, possui a mesma estrutura cúbica da céria e quando inserido a esta ocorre à seguinte equação:

$$
\mathrm{Gd}_{2} \mathrm{O}_{3} \stackrel{2 \mathrm{CeO}_{2}}{\longrightarrow} 2 \mathrm{Gd}_{\mathrm{Ce}}^{\prime}+3 \mathrm{O}^{\mathrm{x}}{ }_{\mathrm{o}}+\mathrm{V}_{\mathrm{o}}
$$

em que, de acordo com a notação de Kröger e Vink [12], $\mathrm{Gd}^{\prime}{ }_{\mathrm{Ce}}$ representa a substituição do íon $\mathrm{Ce}^{4+}$ por um íon $\mathrm{Gd}^{3+}$, $\mathrm{O}^{\mathrm{x}}{ }_{\mathrm{o}}$ representa o íon oxigênio na sua posição normal na rede cristalina, e $\mathrm{V}_{\mathrm{o}}$ é a vacância de oxigênio duplamente ionizada [13]. 
Alguns autores [2, 14] relatam uma maior eficiência catalítica no uso de nanofitas de céria na produção de hidrogênio e na oxidação de monóxido de carbono devido à maior exposição de sítios ativos das famílias de planos $\{001\}$ e $\{110\}$ apresentadas por esse formato. Outros fatores, citados na literatura, que também colaboram com a eficiência catalítica são a presença de vacâncias $[15,16]$ e a propriedade de estocagem de oxigênio da céria [1]. Assim, o tipo e a quantidade de dopantes terras raras inseridos na céria mostram-se promissores para estudos de catálise [1719]. Mas apesar das características interessantes, a maior limitação à aplicação do óxido de cério como catalisador é a sua baixa área de superfície específica, porém quando esta área é próxima de $100 \mathrm{~m}^{2} / \mathrm{g}$, são considerados catalisadores de grande interesse [20]. A céria pode ser obtida por vários métodos, como processo sol-gel [21], síntese assistida por surfactantes [8], hidrotérmico [22], Pechini [23]. Algumas outras técnicas de síntese de pós têm sido utilizadas na preparação do dióxido de cério, entretanto, para fins de síntese em escala superior à laboratorial, a técnica de precipitação continua sendo a mais utilizada por sua conveniente razão custo/benefício, boa reprodutibilidade, alto rendimento e por permitir a obtenção de quantidades em grande escala [4]. Neste trabalho o método de síntese utilizado foi o de coprecipitação e o processamento proposto foi baseado no uso de um sistema hidrotérmico assistido por micro-ondas. $\mathrm{O}$ uso das micro-ondas no processamento de óxidos tem atraído um grande interesse e esta tecnologia pode ser considerada uma alternativa ao tratamento térmico convencional. O aquecimento rápido e volumétrico associado à energia das micro-ondas vem sendo aplicado a vários processos, como a obtenção de materiais cerâmicos, análise química, tratamento de lixo, síntese de polímeros, decomposição de materiais, entre outros [26]. Essa diferença na forma de aquecimento propicia várias vantagens ao processamento de materiais com relação às técnicas de aquecimento convencionais. Como o aquecimento se dá por interação com o campo eletromagnético, ocorre um aquecimento volumétrico do material, o que permite trabalhar com altas taxas de aquecimento e reduzir os ciclos de processamento [25], além de favorecer o crescimento por mecanismo de "oriented attachment" para esse material anisotrópico [26]. Esse sistema tem a vantagem do rápido e homogêneo aquecimento da solução em meio aquoso, resultando numa nucleação homogênea, resultado da supersaturação devida à rápida dissolução do precipitado, e eventualmente, num pequeno tempo de cristalização comparado ao sistema hidrotérmico convencional. O sistema utilizado consiste de um forno de micro-ondas doméstico adaptado contendo um reator de teflon. O sistema completo é composto por termopar, manômetro, válvula de segurança e um forno de micro-ondas adaptado a um controlador de temperatura. A partir dos argumentos citados, estudos de síntese e processamento de materiais à base de céria contribuem na pesquisa de catalisadores para produção de hidrogênio e na fabricação de células a combustível de óxido sólido, que são de grande interesse tecnológico. Neste estudo, os materiais foram preparados pelo método sol-gel de coprecipitação e o objetivo foi estudar o crescimento de nanofitas de céria dopada com gadolínio utilizando um sistema hidrotérmico assistido por micro-ondas.

\section{EXPERIMENTAL}

Síntese e processamento utilizando sistema hidrotérmico assistido por micro-ondas

Todos os reagentes utilizados foram de grau analítico. A céria dopada com gadolínio, com composição nominal $\mathrm{Ce}_{0,8} \mathrm{Gd}_{0,2} \mathrm{O}_{1,9-\delta}$ foi sintetizada pelo método de coprecipitação e processada com tratamento hidrotérmico assistido por micro-ondas.

Inicialmente, as relações estequiométricas foram calculadas, onde para $5 \mathrm{~g}$ de nitrato de cério hexahidratado $\left(\mathrm{Ce}\left(\mathrm{NO}_{3}\right)_{3} \cdot 6 \mathrm{H}_{2} \mathrm{O} 99.9 \%\right.$, Noah Techn. Corp.) foram utilizados 0,2320 g de óxido de gadolínio $\left(\mathrm{Gd}_{2} \mathrm{O}_{3} 99.9 \%\right.$, Noah Techn. Corp.) preparando-se uma solução de 0,1 M. Primeiramente dissolveu-se o óxido de gadolínio em uma quantidade mínima de ácido nítrico, sob agitação e aquecimento e em seguida misturou-se com a solução contendo cério. $\mathrm{O}$ pH da reação foi ajustado para 10, com uma solução de hidróxido de amônio diluído (1:1). Feito o ajuste, a solução apresentou um aspecto de gel com coloração rosada. A mesma passou por um tratamento hidrotérmico a $130{ }^{\circ} \mathrm{C}$ com a pressão do sistema chegando a $3 \mathrm{~atm}$. Esse processamento foi realizado em vários tempos, obedecendo ao critério cinético de tempo de $2^{\text {n }}(n=1,2,3$ e 4$)$ e com uma alta taxa de aquecimento de $150{ }^{\circ} \mathrm{C} / \mathrm{min}$. Após o aquecimento, aguardou-se o resfriamento e logo em seguida o precipitado formado foi filtrado e lavado com água destilada várias vezes por um processo de filtração sob vácuo até a remoção total da amônia. Depois disso foi colocado em um vidro relógio e levado a estufa para secar a $120{ }^{\circ} \mathrm{C}$ durante $24 \mathrm{~h}$.

\section{Caracterizações}

As caracterizações das amostras foram realizadas em um difratômetro de raios X Shimadzu XRD 6100 com radiação $\mathrm{k}_{\alpha}$ do cobre $(40 \mathrm{kV}, 30 \mathrm{~mA}, \lambda=0,15418 \mathrm{~nm})$. Os padrões de difração foram obtidos com medidas de 5 a $75^{\circ}$ com passo de $2 \%$ s. As amostras foram previamente secas a $110^{\circ} \mathrm{C}$ por $12 \mathrm{~h}$ e desaglomeradas em almofariz de ágata. As análises de área de superfície específica dos pós obtidos foram realizadas num aparelho ASAP-2000, pela técnica de adsorção gasosa, com nitrogênio. As morfologias e os tamanhos das nanofitas foram observados em um microscópio eletrônico de transmissão de alta resolução Tecnai F20 FEI a 200 kV.

\section{RESULTADOS E DISCUSSÃO}

O estudo de crescimento das nanofitas de óxido de cério dopado com gadolínio foi feito obedecendo ao critério cinético de tempo de $2^{\mathrm{n}}$, com o tempo em minutos e sendo $\mathrm{n}=$ $1,2,3$ e 4 . O estudo no tempo igual a $30 \mathrm{~min}$ já foi verificado 


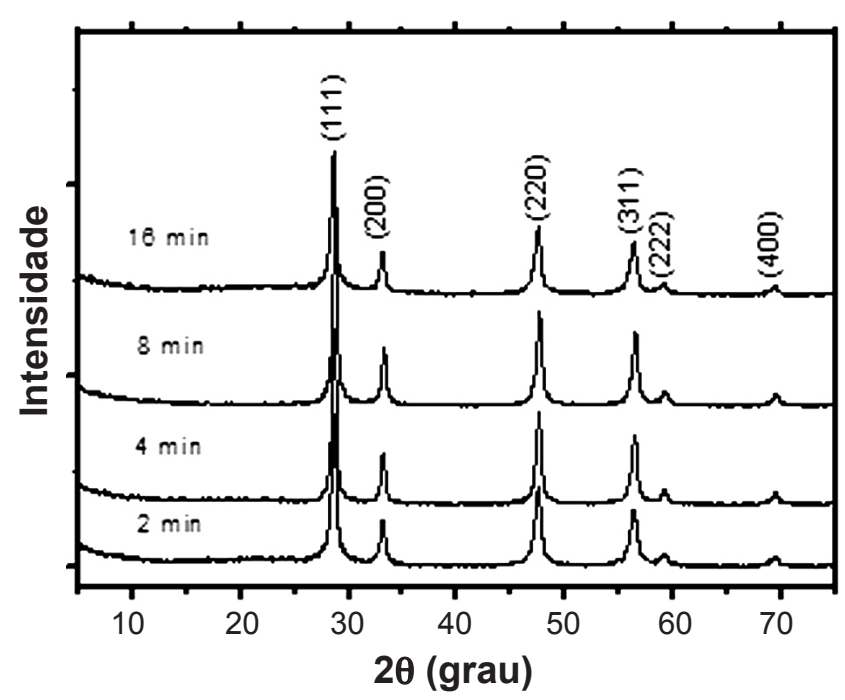

Figura 1: Difratogramas de raios $\mathrm{X}$ da $\mathrm{Ce}_{0,8} \mathrm{Gd}_{0,2} \mathrm{O}_{1,9-\delta}$ em função do tempo de processamento.

[Figure 1: XRD patterns of the $\mathrm{Ce}_{0,8} \mathrm{Gd}_{0,2} \mathrm{O}_{1,9-\delta}$ treated at different times.]

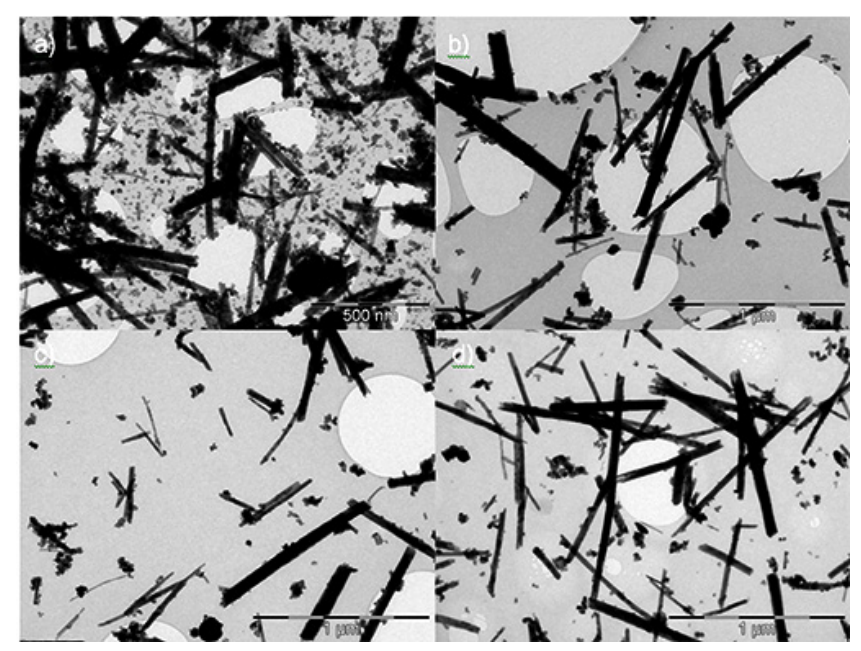

Figura 2: Micrografias de microscopia eletrônica de transmissão de nanofitas de $\mathrm{Ce}_{0,8} \mathrm{Gd}_{0,2} \mathrm{O}_{1,9-\delta}$ processada em a) $2 \mathrm{~min}$, b) $4 \mathrm{~min}$, c) 8 min e d) 16 min.

[Figure 2: TEM micrographs of $\mathrm{Ce}_{0.8} \mathrm{Gd}_{0.2} \mathrm{O}_{1.9-8}$ nanobelts processed during a) $2 \mathrm{~min}$, b) $4 \mathrm{~min}, \mathrm{c}) 8 \mathrm{~min}$ and d) $16 \mathrm{~min}$.]

[28] e os resultados são semelhantes aos do tempo 16 min. Desta forma, tempos superiores a $30 \mathrm{~min}$ para aquecimento com micro-ondas não são de interesse científico. A Fig. 1 mostra os difratogramas de raios $\mathrm{X}$ desses materiais em diferentes tempos de processamento (2, 4, 8 e $16 \mathrm{~min})$. Para todos os tempos de processamento, as amostras apresentaram picos de difração característicos de estrutura cúbica do tipo fluorita, comprovada pela comparação com o arquivo JCPDS 34-0394.

Após a caracterização estrutural, as morfologias dos pós de $\mathrm{Ce}_{0,8} \mathrm{Gd}_{0,2} \mathrm{O}_{1,9-\delta}$ foram investigadas pela técnica de microscopia eletrônica de transmissão (MET). Na Fig. 2 são apresentadas as micrografias obtidas por MET, nas quais é observada a formação de nanofitas e de nanopartículas irregulares.

Os resultados na Fig. 2 estão de acordo com os reportados [26], em que a céria é produzida pelo mesmo método proposto neste trabalho. Também foi observada a formação consecutiva de nanopartículas irregulares e de nanofitas. Foi proposto que as nanofitas de $\mathrm{Ce}_{0,8} \mathrm{Gd}_{0,2} \mathrm{O}_{1,9-\delta}$ se originam a partir de nanopartículas irregulares. Esperava-se um desaparecimento das nanopartículas irregulares com o aumento do tempo de tratamento térmico, porém os resultados a seguir mostram que é possível uma otimização neste processo.

Para verificar a área de superfície específica, as amostras foram analisadas pela técnica de BET, Tabela I.

A partir dos resultados de BET e de difração de raios X é possível concluir que em 8 min há uma diminuição da área de superfície específica e um aumento na intensidade das reflexões dos planos de difração (111), ou seja, a diminuição da área de superfície específica é relativa a uma diminuição da quantidade de partículas irregulares. Este resultado mostra que há uma transformação/incorporação das partículas irregulares para nanofitas, ou seja, ocorre uma diminuição considerável das nanopartículas de morfologia irregular em detrimento da formação das nanofitas. No entanto, em tempos maiores que $8 \mathrm{~min}$, o número de partículas irregulares volta a aumentar atingindo um equilíbrio em tempos maiores que 8 min. A quantificação do comprimento das nanofitas foi realizada por medidas das micrografias obtidas e os resultados são mostrados no histograma da Fig. 3.

A evolução da mudança no tamanho médio das nanofitas em função do tempo é melhor visualizada na Fig. 4. Como citado anteriormente, tempo de $30 \mathrm{~min}$ já foram investigados [26] mostrando-se semelhante aos resultados no tempo de 16 min e por isso não serão mostrados.

Este estudo de otimização do processamento das nanofitas de céria pode vir a colaborar com a aplicação deste material no anodo de células a combustível de óxido sólido. Nestas células são utilizadas misturas de óxido de cério e níquel para formar o cermet (cerâmica-metal). Novos materiais estão sendo estudados para substituição de compósitos cerâmica-metal à base de $\mathrm{ZrO}_{2}: \mathrm{Y}_{2} \mathrm{O}_{3} / \mathrm{Ni}$, pois apesar de ter ótima atividade catalítica e boa condutividade elétrica, estes compósitos apresentam algumas limitações. Dentre essas, destacam-se a baixa resistência a ciclos de oxidação-redução e a formação de depósitos de carbono no anodo. Entretanto a deposição de carbono nas nanofitas de céria é menor, comparada às partículas irregulares comumente utilizadas nesses anodos [2]. Além disso, o cermet tem que ser processado com uma estrutura porosa para permeação dos gases combustíveis; assim, a sinterização desse tipo de material é adequada para obtenção de microestruturas porosas. Deve-se lembrar também que o cermet é responsável pela quebra catalítica dos combustíveis tais como $\mathrm{H}_{2}, \mathrm{CO}$ e $\mathrm{CH}_{4}$. Devido a essa flexibilidade no uso dessa gama de combustíveis, essas nanofitas apresentam grande potencial para serem utilizadas como no cermet no anodo ou em reformadores.

$\mathrm{O}$ uso das nanofitas em reforma a vapor do etanol gera como produtos os seguintes constituintes mostrados na reação [2]: 


$$
\mathrm{C}_{2} \mathrm{H}_{5} \mathrm{OH} \rightarrow \mathrm{H}_{2}+\mathrm{CO}+\mathrm{CH}_{4}
$$

ou seja, esses 3 produtos $\left(\mathrm{H}_{2}, \mathrm{CO}\right.$ e $\left.\mathrm{CH}_{4}\right)$ são combustíveis citados anteriormente e são utilizados em células a combustível de óxido sólido. As células a combustível convertem energia química diretamente em energia elétrica com eficiência termodinâmica não limitada pelo ciclo de Carnot e essa vantagem depende, entretanto, de como os combustíveis que serão utilizados podem ser reformados

Tabela I - Tamanho médio de cristalito e área de superfície específica BET das amostras de céria dopada com gadolínia. [Table I - Average crystallite size, and BET specific surface area of gadolinium-doped ceria.]

\begin{tabular}{ccc}
\hline $\begin{array}{c}\text { tempo } \\
(\mathrm{min})\end{array}$ & $\begin{array}{c}\text { Tamanho médio } \\
\text { de cristalito }(\mathrm{nm})\end{array}$ & $\begin{array}{c}\text { BET } \\
\left(\mathrm{m}^{2} / \mathrm{g}\right)\end{array}$ \\
\hline 2 & 5,8 & 108 \\
4 & 13,4 & 96 \\
8 & 18,7 & 89 \\
16 & 15,3 & 98 \\
\hline
\end{tabular}
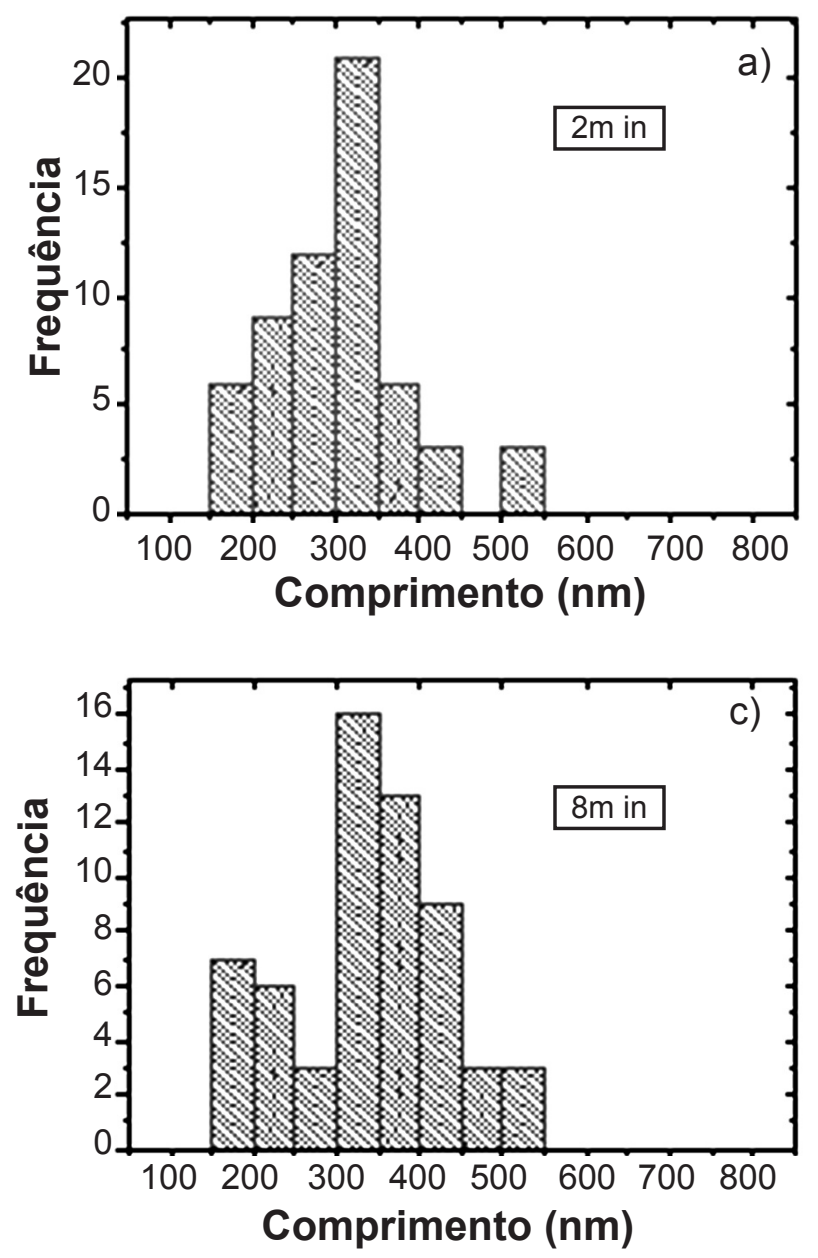

Figura 3: Histogramas de distribuição de comprimento das nanofitas. [Figure 3: Histogram distribution of nanobelt lengths.] para produzir hidrogênio e dióxido de carbono. Além disso, o material do anodo deve possuir, nas condições de operação da célula a combustível, boa estabilidade física e química, compatibilidade química e estrutural com o eletrólito e o interconector, alta condutividade eletrônica e iônica e atividade catalítica para a oxidação do combustível [27]. Portanto este estudo contribui com as pesquisas em células a combustível de óxido sólido utilizando nanofitas de céria dopada com gadolínio no anodo, viabilizando desta forma, sua aplicação como catalisadores.

\section{CONCLUSÕES}

Os estudos mostraram que o tempo reacional de processamento para obter nanofitas com maior comprimento e largura foi $8 \mathrm{~min}$. Nesse tempo foram obtidas nanofitas com largura média $23 \mathrm{~nm}$ e comprimento médio $330 \mathrm{~nm}$, com área de superfície específica $89 \mathrm{~m}^{2} / \mathrm{g}$ e tamanho médio de cristalito 18,7 nm. Estes resultados evidenciam que o uso do método de coprecipitação associado ao sistema hidrotérmico assistido por micro-ondas é eficaz para obtenção de nanofitas de céria dopada com gadolínio. Essa técnica é, portanto, interessante não somente devido
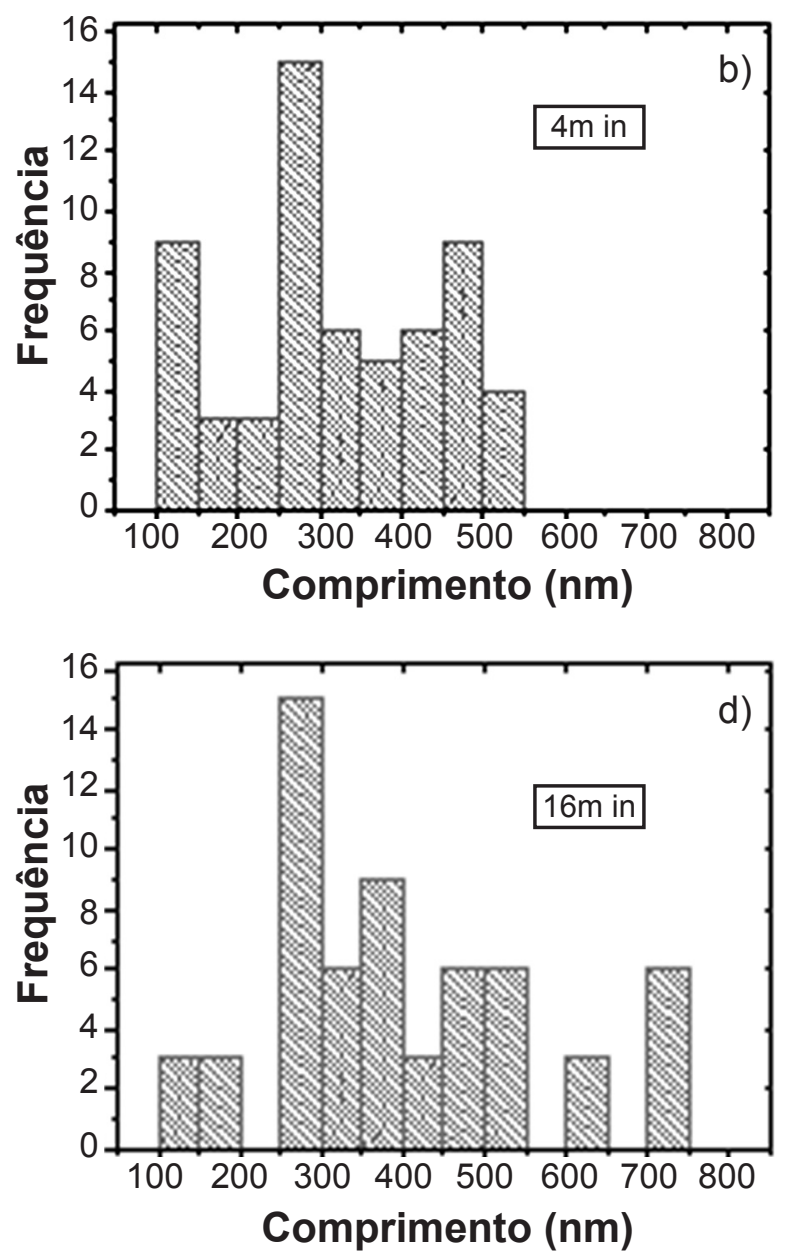

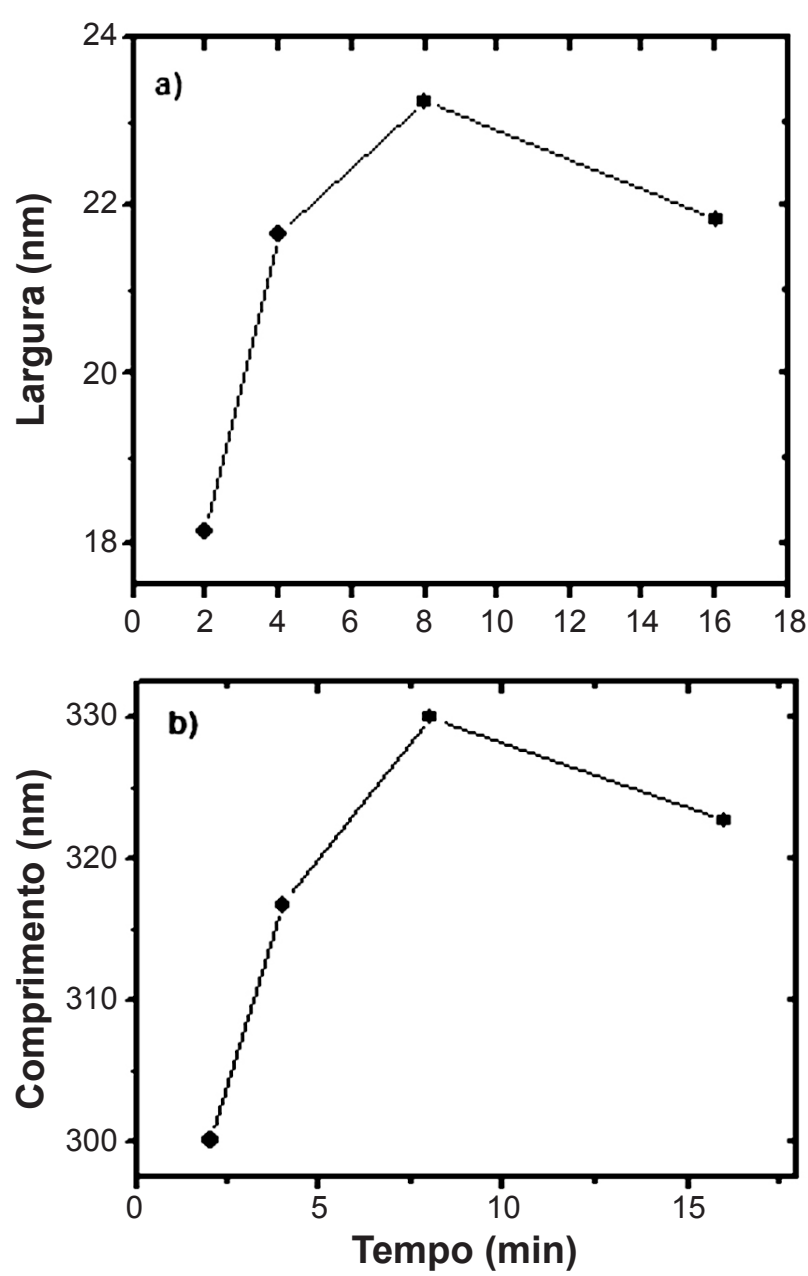

Figura 4: Evolução do tamanho médio das nanofitas com o tempo: a) largura e b) comprimento.

[Figure 4: Evolution of the average nanobelt size with time: a) width and b) length.]

aos tempos de processamento e temperatura reduzidos, mas também pela possibilidade de obtenção de pós com propriedades controladas. A utilização destas nanofitas de $\mathrm{Ce}_{0,8} \mathrm{Gd}_{0,2} \mathrm{O}_{1,9-\delta}$ na fabricação de anodos para células a combustível e na reforma do etanol será fonte para futuros estudos.

\section{AGRADECIMENTOS}

Os autores agradecem o suporte financeiro das agências de fomento CAPES, CNPq, FAPESP e FAPEG. Especial agradecimento ao Sr. Rorivaldo Camargo pelas imagens de MET, ao INCTMN/CNPq e ao Departamento de Química CAC-UFG.

\section{REFERÊNCIAS}

[1] A. Bumajdad, J. Eastoe, A. Mathew, Adv. Colloid Interface Sci. 147 (2009) 56.

[2] M. J. Godinho, R. F. Gonçalves, E. R. Leite, C. W. Raubach, N. L. V. Carreno, L. F. D. Probst, E. Longo, H. V.
Fajardo, J. Mater. Sci. 45 (2010) 593.

[3] X. Sha, Z. Lu, X. Huang, J. Miao, L. Jia, X. Xin, W. Su, J. Alloys Compoun. 424, 1 (2006) 315.

[4] E. N. S. Muccillo, T. C. Porfírio, S. K. Tadokoro, J. F. Q. Rey, R. A. Rocha, M. C. Steil, R. Muccillo, Cerâmica 51, 318 (2005) 157.

[5] A. M. T. Silva, R. Marques, R. M. Quinta-Ferreira, Appl. Catal. B: Environmental 47 (2004) 269.

[6] S. Imamura, A. Doi, S. Ishida, Ind.1 \& Eng. Chem. Product Res. Development 24 (1985) 75.

[7] W. Yao, Y. Chen, L. Min, H. Fang, Z. Yan, H. Wang, J. Molecular Catal. A-Chem. 246 (2006) 162.

[8] N. Al-Haq, A. C. Sullivan, J. R. H. Wilson, Tetrahedron Lett. 44 (2003) 769.

[9] V. Fernandes, P. Schio, A. J. A. Oliveira, W. A. Ortiz, P. F. P. Fichtner, L. Amaral, I. L. Graff, J. Varalda, N. Mattoso, W. H. Schreiner, D. H. Mosca, J. Phys. Cond. Matter 22 (2010) P9.

[10] G. B. Crochemore, D. P. F. Souza, Rev. Matéria 14 (2009) 1076.

[11] S. Dikmen, P. Shuk, M. Greenblatt, H. Gocmez, Solid State Sci. 4 (2002) 585.

[12] F. A. Kroger, H. J. Vink, Solid State Phys. 3 (1956) 223.

[13] R. A. Rocha, E. N. S. Muccillo, Cerâmica 47, 304 (2001) 304.

[14] K. Zhou, X. Wang, X. Sun, Q. Peng, Y. Li, J. Catalysis 229 (2005) 206.

[15] Q. Wu, R. van de Krol, J. Am. Chem. Soc. 134 (2012) 9369.

[16] X. Chen, H. Wang, S. Gao, Z. Wu, J. Colloid Interface Sci. 377 (2012) 131.

[17] S. C. Dantas, K. A. Resende, R. L. Rossi, A. J. Assis, C. E. Hori, Chem. Eng. J. 197 (2012) 407.

[18] K. Yashiro, T. Suzuki, A. Kaimai, H. Matsumoto, Y. Nigara, T. Kawada, J. Mizusaki, J. Sfeir, J. Van Herle, Solid State Ionics 175 (2004) 341.

[19] S. Zeng, W. Zhang, S. Guo, H. Su, Catalysis Comm. 23 (2012) 62.

[20] J. L. Carter, J. A. Cusumano, J. H. Sinfelt, J. Phys. Chem. 70 (1966) 2257.

[21] M. Sidheswaran, L. L. Tavlarides, Ind. Eng. Chem. Res. 47 (2008) 3346.

[22] M. M. Titirici, M. Antonietti, A. Thomas, Chem. Mater. 18 (2006) 3808.

[23] C. Sánchez-Bautista, A. J. Dos Santos-García, J. PeñaMartínez, J. Canales-Vázquez, Solid State Ionics 181 (2010) 1665 .

[24] D. Baek, U. Y. Hwang, K. S. Lee, J. Ind. Eng. Chem. 7 (2001) 241.

[25] R. R. Menezes, P. M. Souto, R. H. G. A. Kiminami, Cerâmica 53, 327 (2007) 218.

[26] M. Godinho, C. Ribeiro, E. Longo, E. R. Leite, Crystal Growth \& Design 8 (2008) 384.

[27] D. Z. de Florio, F. C. Fonseca, E. N. S. Muccillo, R. Muccillo, Cerâmica 50, 316 (2004) 275.

(Rec. 31/10/2012, Rev. 04/02/2013, 18/02/2013, 21/02/2013, Ac. 21/02/2013) 